\title{
Adolescência e Drogas: Representações Sociais e Atribuições de Causalidade ao Uso
}

\section{Adolesciencia y Drogas: Representaciones Sociales y Atribución de Causalidad al Uso}

\author{
Adolescence and Drugs: Social Representations and Causal Attribution to Use
}

Ivana Lauffer Corrêa

Universidade Federal de Santa Catarina (UFSC), Florianópolis - SC/Brasil ORCID: 0000-0003-3811-628X

E-mail: ivanalauffer@gmail.com

Jean Paulo da Silva

Universidade Federal de Santa Catarina (UFSC), Florianópolis - SC/Brasil ORCID: 0000-0001-5173-1856

E-mail: jeanps.silva@gmail.com

\author{
Andréa Barbará da Silva Bousfield \\ Universidade Federal de Santa Catarina (UFSC), Florianópolis - SC/Brasil \\ ORCID: 0000-0002-4333-4719
}

E-mail: andreabs@gmail.com

Andréia Isabel Giacomozzi

Universidade Federal de Santa Catarina (UFSC), Florianópolis - SC/Brasil ORCID: 0000-0002-3172-5800

E-mail: agiacomozzi@hotmail.com

\begin{abstract}
Resumo
Tratou-se de um estudo descritivo e comparativo com a participação de 262 adolescentes de ambos os sexos estudantes do ensino médio de cinco cidades do sul do Brasil. Foi utilizado um questionário estruturado composto por questões abertas e fechadas e técnica de Evocação Livre de Palavras para investigação das representações sociais. Os resultados indicam que para os participantes a representação social das drogas se organiza em torno de um núcleo central composto por ideias ligadas às consequências do uso como: vício, tráfico, dependência, destruição e violência. Também estão presentes elementos como maconha, álcool e remédios. A zona periférica da representação apresenta sobretudo elementos negativos associados à desdobramentos do vício associados à morte, problemas de saúde e familiares. Para os adolescentes a noção de droga se estrutura principalmente em torno dos elementos vício, maconha e morte. Para eles, o que leva alguém a usar drogas é a influência de outras pessoas, problemas familiares, curiosidade, necessidade de aceitação entre os pares, e falta de informação. Conclui-se que para o enfrentamento dos problemas decorrentes do uso de drogas na sociedade, há necessidade de desenvolvimento de programas de intervenção educacional que considerem o pensamento social produzido pelos diferentes grupos sociais.
\end{abstract}

Palavras-chaves: Adolescentes; Drogas; Saúde mental; Conhecimento.

\section{Resumen}

Este es un estudio descriptivo y exploratorio con la participación de 262 adolescentes de ambos sexos, estudiantes de secundaria de cinco ciudades del sur de Brasil. Se utilizó un cuestionario estructurado compuesto por preguntas abiertas y cerradas y técnica de Evocación Libre de Palabras para investigar las representaciones sociales. Los resultados indican que la representación social de las drogas para los participantes se organiza en torno a un núcleo central compuesto de ideas vinculadas a las consecuencias del uso, tales como: adicción, tráfico, dependencia, destrucción y violencia. Elementos como la marihuana, el alcohol y la medicina también están presentes. El área periférica de la representación presenta 
principalmente elementos negativos asociados con el desarrollo de la adicción asociada con la muerte, la salud y los problemas familiares. Para los adolescentes, la noción de drogas se estructura principalmente en torno a los elementos de adicción, marihuana y muerte. Para ellos, lo que impulsa a alguien a usar drogas es la influencia de otras personas, los problemas familiares, la curiosidad, la necesidad de aceptación entre sus compañeros y la falta de información. Se concluye que para enfrentar los problemas derivados del uso de drogas en la sociedad, es necesario desarrollar programas de intervención educativa que consideren el pensamiento social producido por diferentes grupos sociales.

Palabras clave: Adolescentes; Drogas; Salud mental; Conocimiento.

\begin{abstract}
This is a descriptive and exploratory study with the participation of 262 adolescents of both sexes, high school students from five cities in southern Brazil. A structured questionnaire composed of open and closed questions and the Free Word Evocation technique was
\end{abstract}

used to investigate social representations. The results indicate that the social representation of drugs for the participants are organized around a central nucleus composed of ideas linked to the consequences of use such as: addiction, dealing, dependence, destruction and violence. Elements such as marijuana, alcohol, and medicine are also present. The peripheral area of the representation mainly presents negative elements associated with the unfolding of addiction associated with death, health and family problems. For teenagers, the notion of drugs is mainly structured around the elements of addiction, marijuana and death. For them, what drives people to use drugs is the influence of other people, family problems, curiosity, need for acceptance among peers, and lack of information. It is concluded that in order to face the problems arising from the use of drugs in society, is necessary to develop educational intervention programs that consider the social thinking produced by different social groups.

Keywords: Teenagers; Drugs; Mantal health; Knowledge.

\section{Introdução}

Ao longo da história o uso de drogas se fez presente em inúmeras sociedades e contextos culturais e com os mais diversos objetivos, como transcendência, sobrevivência, e também rituais, tanto sagrados quanto profanos. No entanto, essas substâncias passaram a ser utilizadas indiscriminadamente e em muitos contextos seu uso abusivo se desdobrou em complicações físicas, psicológicas e sociais. O abuso de drogas é compreendido como um relevante problema social e de saúde pública (Kristjansson, Sigfusdottir, Allegrante \& Helgason, 2008), estando presente em debates nas várias esferas da vida individual e social, declarando uma natureza polissêmica e estreitamente vinculada às problemáticas da vida na contemporaneidade (Melo, 2013; Seleghim, Marangoni, Marco \& Oliveira, 2011).

O aumento da prática de uso de drogas pelos adolescentes tem sido observado em todo o mundo. No último relatório mundial sobre drogas (Nações Unidas sobre Drogas e Crime [UNODC], 2019) há estimativa de que mais de 270 milhões de pessoas, incluindo adolescentes fizeram uso de algum tipo de droga ilícita no ano de 2018. Estes dados representam um aumento de $30 \%$ em relação ao ano de 2009. Além disso, a precocidade do uso tem sido cada vez maior (Carlini et al., 2010). No contexto brasileiro, o III Levantamento Nacional Sobre o Uso de Drogas Pela População Brasileira, publicado pela FIOCRUZ informa que 34,3\% dos adolescentes entre 12 e 17 anos relataram ter feito uso de bebidas alcoólicas em algum momento da vida, $6,3 \%$ tabaco e $4 \%$ algum tipo de droga ilícita (Bastos, Vasconcellos, De Boni, Reis \& Coutinho, 2017).

O termo adolescente, derivado latim, remete a uma noção de brotar, crescer e desenvolver força. É considerada uma fase de transição da infância para a fase adulta, de uma condição de dependência para a busca de autonomia (Organização Mundial da Saúde [OMS], 1995). Este período, marcado por transformações biopsicossociais importantes é decisivo para o desenvolvimento de competências e aquisição de habilidades pessoais e interpessoais que impactam na tomada de decisão (Malta et al., 2010; Giacomozzi, Itokasu, Figueiredo, Luzardo, \& Vieira, 2012). 
O uso de drogas na adolescência é um importante fator de risco ao desenvolvimento e está associado ao aumento da vulnerabilidade, baixo rendimento escolar, problemas sociais ou interpessoais, baixa autoeficácia, e exposição à outros comportamentos de risco como relações sexuais precoces e desprotegidas, e situações de violência (Essau, 2011; Giacomozzi et al., 2012).

No âmbito das ações preventivas em saúde, melhores resultados podem ser alcançados quando as intervenções envolvem aspectos afetivos, cognitivos e sociais, e com conteúdo informativo repassado de maneira abrangente (Czeresnia, 2003; Minto, Pedro, Netto, Bugliani, \& Gorayeb, 2006). Para que isso ocorra no contexto do uso de drogas, é necessário conhecer o fenômeno que envolve a prática de uso a partir de suas várias dimensões, considerando o pensamento social que circula nos grupos a respeito desse objeto um importante foco de atenção. Sendo a adolescência um período marcado por descobertas, transformações e instabilidades emocionais, a compreensão contextualizada dos aspectos socioculturais é fundamental, não podendo assim reduzir essa fase a uma simples noção de faixa etária (Fonseca, Sena, Santos, Dias \& Costa, 2013).

Considerando a importância do fenômeno do uso drogas, a Teoria das Representações Sociais (TRS), como um paradigma do pensamento social, contribui com a compreensão dos aspectos sociocognitivos que constituem papel crucial na construção de formas coletivas de significar essa prática, divulgando formas de pensamento e de comportamento a elas associados. Para Jodelet (2001) as representações sociais são uma forma de conhecimento, elaborada $\mathrm{e}$ partilhada no âmbito social, e que possuem um objetivo prático, colaborando para que seja construída uma realidade comum a um grupo social. Assim, como sistemas de interpretações que gerenciam a relação entre indivíduoindivíduo e indivíduo-mundo (Jodelet, 2001) as representações sociais possuem tanto uma função de orientação, pois direcionam comportamentos e práticas sociais assumindo um caráter preditor da relação das pessoas com os objetos sociais, quanto uma função justificadora, pois tem característica de validar comportamentos realizados que são integrados a um referencial de identificação grupal e adequação às práticas sociais comuns ao grupo (Abric, 1998).

As drogas estão presentes no mundo e alimentam compreensões diversas acerca de seus efeitos no indivíduo e na sociedade, evidenciando seu caráter de ação biológico, psicológico e seu papel social para os indivíduos (Soares-Filho, 2017). Enquanto fenômeno, as drogas constituem elementos que demandam a reflexão acerca da construção social de uma problemática que atravessa tempo, espaço, culturas e gerações, estabelecendo uma memória social carregada de concepções que influenciam na forma de interação com esse objeto.

Assim, tendo em vista que na interação com o meio os indivíduos se utilizam do conhecimento socialmente produzido e compartilhado para lidar com a realidade, transformando o que é não-familiar em algo familiar e conhecido (Moliner, 2009) evoca-se também a necessidade de abordar a interação entre as representações sociais e as atribuições de causalidade ao uso de drogas, uma vez que as atribuições são mecanismos que permitem ao ser humano perceber os acontecimentos cotidianos a partir de uma estrutura causal (Hewstone, 2001). Assim, a integração entre as representações sociais e as atribuições de causalidade podem dar conta da inter-relação entre o coletivo e o individual, o histórico e o situacional (Blaudt \& Rangel, 2018).

Por fim, o uso de drogas é um fenômeno complexo, multifacetado e que tem apresentado índices elevados de ocorrência na população brasileira, todavia, a produção de conhecimento teórico e prático que possibilite ações eficazes parece ainda insuficiente. Dessa forma, conhecer as representações sociais dos adolescentes sobre as drogas pode propiciar a elaboração de ações em saúde direcionadas às demandas específicas associadas aos saberes compartilhados e que circulam nesse grupo, 
proporcionando desfechos positivos tanto para o contexto individual dos adolescentes, quanto familiar e comunitário.

\section{Método}

Tratou-se de um estudo descritivo e exploratório com a participação de 262 adolescentes de ambos os sexos estudantes do ensino médio de cinco cidades do sul do Brasil. Para coleta de dados foi utilizado um questionário semi-estruturado composto de questões abertas e fechadas utilizando técnica de Evocação Livre de Palavras para investigação das representações sociais, e questões abertas que tratam da atribuição de causa ao uso de drogas. Por fim, havia um bloco de questões de caracterização sociodemográfica.

$\mathrm{O}$ instrumento foi aplicado em modalidade autoadministrada no ambiente de sala de aula, onde após o recolhimento dos Termos de Consentimento Livre e Esclarecido assinados pelos responsáveis e o Termo de Assentimento dos adolescentes, foram distribuídos os questionários e lidas as instruções pelas pesquisadoras responsáveis pela aplicação.

Para análise dos dados quantitativos foi empregado uso de estatística descritiva (medidas de dispersão e centralidade e distribuição de frequências) e inferencial (Quiquadrado, T-Student e Mann-Whitney) por meio do Software Statistical Package for Social Sciences - SPSS versão 17.0.

Os dados da Técnica de Evocação Livre de Palavras (TALP) proposta e desenvolvida por Vergès (1992), foram submetidos à análise prototípica e de similitude utilizando o software para análise quantitativa de dados textuais IRaMuTeQ (Ratinaud, 2009). Essa técnica foi utilizada para investigar os possíveis elementos que compõem a estrutura das representações sociais a partir das respostas ao termo indutor "drogas". Assim, os participantes foram solicitados a evocar livremente cinco palavras que lhes ocorressem ao ler o termo indutor, em seguida realizar a escolha das duas palavras consideradas mais importantes dentre elas. Por fim os dados textuais das respostas às perguntas abertas foram analisados por meio de Classificação Hierárquica Descendente (CHD) também com uso do IRaMuTeQ.

Ressalta-se que a pesquisa seguiu todos os procedimentos éticos preconizados pela portaria 510/2016 do Conselho Nacional de Saúde, tendo sido aprovada pelo Comitê de Ética em Pesquisas com Seres Humanos sob o parecer n. 2878951.

\section{Resultados}

Da amostra total $(\mathrm{N}=262)$ obteve-se $162(61,8 \%)$ do sexo feminino e $100(38,2 \%)$ masculino. A média de idade foi de 16 anos e 7 meses com desvio padrão de 1 ano. Além disso $60,3 \%$ dos adolescentes se declararam brancos, $25,2 \%$ pardos, $12,2 \%$ negros e 2,3\% indígenas. Em relação à série em que estavam matriculados, observou-se que $36,6 \%$ estavam no $1^{\circ}$ ano, $34,7 \%$ no $2^{\circ}$ ano, e $28,6 \%$ no $3^{\circ}$ ano.

\section{Representações sociais das drogas para os adolescentes}

As evocações produzidas pelos participantes no TALP, conforme orienta a técnica, foram registradas na ordem em que foram lembradas, permitindo assim obter duas medidas de dados para análise: a frequência de evocação de cada palavra (número de vezes citada) e a ordem média de evocação (OME), que representa o quão prontamente foi lembrada pelo respondente.

Com relação ao conteúdo geral das RS sobre as drogas, ativado a partir da TALP do corpus, foram realizadas 1.301 evocações, de 325 palavras diferentes. A Figura 1 foi desenvolvida para apresentar de maneira geral as palavras evocadas e suas frequências em cada uma das posições (rangs). Destacam-se as palavras vício, morte e maconha com alta frequência de evocação nas primeiras posições. 


\begin{tabular}{|c|c|c|c|c|c|c|c|c|c|c|c|c|c|c|}
\hline Evoc-Rang 1 & $f$ & $\%$ & Evoc-Rang 2 & $f$ & $\%$ & Evoc-Rang 3 & $f$ & $\%$ & Evoc-Rang 4 & $f$ & $\%$ & Evoc-Rang 5 & $f$ & $\%$ \\
\hline vício & 53 & 20.31 & morte & 21 & 8.05 & maconha & 15 & 5.75 & morte & 18 & 6.9 & morte & 16 & 6.23 \\
\hline maconha & 30 & 11.49 & vício & 20 & 7.66 & morte & 15 & 5.75 & maconha & 12 & 4.6 & crack & 9 & 3.5 \\
\hline morte & 16 & 6.13 & maconha & 14 & 5.36 & vício & 12 & 4.60 & doença & 9 & 3.45 & família & 9 & 3.5 \\
\hline dependência & 11 & 4.21 & tráfico & 12 & 4.6 & crack & 9 & 3.45 & tráfico & 9 & 3.45 & tristeza & 9 & 3.5 \\
\hline tráfico & 9 & 3.45 & cocaína & 10 & 3.83 & família & 8 & 3.07 & vício & 9 & 3.45 & vício & 9 & 3.5 \\
\hline destruição & 8 & 3.07 & doença & 9 & 3.45 & doença & 7 & 2.68 & depressão & 7 & 2.68 & cocaína & 7 & 2.72 \\
\hline álcool & 6 & 2.30 & álcool & 7 & 2.68 & dependência & 6 & 2.30 & destruição & 7 & 2.68 & doença & 7 & 2.72 \\
\hline doença & 6 & 2.30 & cigarro & 6 & 2.3 & tristeza & 6 & 2.30 & cocaína & 6 & 2.3 & tráfico & 6 & 2.33 \\
\hline festa & 6 & 2.30 & crack & 6 & 2.3 & álcool & 5 & 1.92 & tristeza & 6 & 2.3 & ilícitas & 5 & 1.95 \\
\hline remédios & 5 & 1.92 & dependência & 6 & 2.3 & cocaína & 5 & 1.92 & álcool & 4 & 1.53 & roubo & 5 & 1.95 \\
\hline ruim & 5 & 1.92 & tristeza & 5 & 1.92 & tráfico & 5 & 1.92 & crack & 4 & 1.53 & cigarro & 4 & 1.56 \\
\hline cocaína & 4 & 1.53 & destruição & 4 & 1.53 & adolescentes & 4 & 1.53 & influência & 4 & 1.53 & dependência & 4 & 1.56 \\
\hline perdição & 4 & 1.53 & família & 4 & 1.53 & depressão & 4 & 1.53 & remédios & 4 & 1.53 & destruição & 4 & 1.56 \\
\hline amigos & 3 & 1.15 & cadeia & 3 & 1.15 & problemas & 4 & 1.53 & roubo & 4 & 1.53 & festas & 4 & 1.56 \\
\hline crack & 3 & 1.15 & dependente & 3 & 1.15 & solidão & 4 & 1.53 & amigos & 3 & 1.15 & lança-perfume & 4 & 1.56 \\
\hline dinheiro & 3 & 1.15 & ilícitas & 3 & 1.15 & cigarro & 3 & 1.15 & bala & 3 & 1.15 & loucura & 4 & 1.56 \\
\hline vida & 3 & 1.15 & influências & 3 & 1.15 & pó & 3 & 1.15 & dor & 3 & 1.15 & álcool & 3 & 1.17 \\
\hline \multirow[t]{6}{*}{ violência } & 3 & 1.15 & jovens & 3 & 1.15 & pobreza & 3 & 1.15 & famlia & 3 & 1.15 & bala & 3 & 1.17 \\
\hline & & & morador de rua & 3 & 1.15 & saúde & 3 & 1.15 & morador de rua & 3 & 1.15 & dependente & 3 & 1.17 \\
\hline & & & ruim & 3 & 1.15 & sofrimento & 3 & 1.15 & prisão & 3 & 1.15 & desespero & 3 & 1.17 \\
\hline & & & saúde & 3 & 1.15 & violência & 3 & 1.15 & problemas & 3 & 1.15 & perigo & 3 & 1.17 \\
\hline & & & & & & & & & solidão & 3 & 1.15 & saúde & 3 & 1.17 \\
\hline & & & & & & & & & traficantes & 3 & 1.15 & solidão & 3 & 1.17 \\
\hline
\end{tabular}

Figura 1. Demonstrativo dos elementos evocados a partir da TALP

Nota: Figura elaborada pelos autores

A partir das palavras evocadas observase que há predominância de elementos que indicam ideias negativas em relação às drogas, tanto a partir da análise global de frequências quanto da análise por ordem de evocação, onde se destacam o elemento vício aparecendo com a maior frequência geral (103), seguido de $\underline{\text { morte }}(86)$, maconha (73), tráfico (41) e doença (38).

Visando investigar a RS das drogas para os adolescentes, foi empreendida a análise prototípica das evocações. Esse tipo de análise é essencial aos estudos de RS, pois por meio da ordem das evocações e da frequência das palavras evocadas é possível acessar a estrutura da representação social (Wachelke \& Wolter, 2011; Flament, Guimelli \& Abric, 2006).

Logo, esta análise busca verificar, a partir das 1.301 evocações realizadas e das 325 palavras diferentes, como as representações sociais sobre drogas para os participantes se estruturam. A Figura 2 foi construída a partir da frequência média igual, maior ou menor do que 11 evocações, se referindo à frequência média para distinguir elementos com frequência alta e baixa. A ordem média de evocação (OME) foi de 2,91 .

No primeiro quadrante, superior esquerdo, destacaram-se os elementos vício, maconha, tráfico, dependência, álcool,

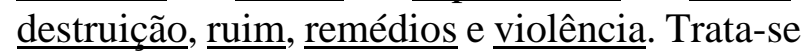
dos elementos que compõem o possível núcleo central da representação, por terem frequência elevada em relação aos outros quadrantes e OME baixa, indicando que foram lembrados pelos participantes entre as primeiras palavras. Desta forma, tem-se uma primeira ideia da representação social das drogas para os adolescentes: as drogas são ruins, levam ao vício e estão associadas a consequências como violência, destruição e tráfico. A palavra remédios aparece como marcador da classificação das drogas, tendo em vista que medicamentos também são utilizados como drogas de abuso. Ressalta-se que a maioria dos termos evocados no possível núcleo central exprimem um contexto negativo associado às drogas, sendo elementos unificadores e estabilizadores das representações sociais desse objeto.

No segundo quadrante, superior direito, chamado de primeira periferia, se encontram os elementos evocados que indicam elementos periféricos com alto grau de ativação. São os elementos: morte, doença, cocaína, crack, tristeza, família, cigarro, depressão, ilícitas, saúde, roubo, solidão e problemas. Esses elementos remetem ao primeiro quadrante, com características predominantemente negativas, 
ou seja, aspectos que ligados aos desdobramentos do vício. Estes levam à morte, acarretam doenças, problemas de saúde e problemas familiares, sobretudo quando o uso é de substâncias como o crack e a cocaína. Além disso, pode haver um indicativo para problemas de ordem social, quanto ao sentido da palavra roubo. Observa-se que tais elementos objetificam e tornam pragmáticas as normas e valores presentes no núcleo da RS.

No terceiro quadrante, inferior esquerdo, chamado de área de contraste, aparecem termos associados principalmente ao contexto de uso das drogas, a oferta de drogas em festas e a influência de amigos que pode acarretar na experimentação e em seus desdobramentos, apesar dos riscos. Por fim, a chamada periferia longínqua se encontra no quarto quadrante, $\mathrm{o}$ inferior direito, contrastando com a zona do núcleo e trata-se das representações individuais ou de subgrupos, aspectos menos compartilhados da RS.

\begin{tabular}{|c|c|c|c|c|c|c|}
\hline \multicolumn{7}{|c|}{ Evocações a partir do termo indutor "Drogas" $(n=262)$} \\
\hline & OM & $=2$. & & ON & 2.9 & \\
\hline \multirow{14}{*}{$f>=11$} & Elemento & $\boldsymbol{f}$ & OME & Elemento & $f$ & OME \\
\hline & vício & 103 & 2.0 & morte & 86 & 3.0 \\
\hline & maconha & 73 & 2.2 & doença & 38 & 3.1 \\
\hline & tráfico & 41 & 2.8 & cocaína & 32 & 3.1 \\
\hline & dependência & 29 & 2.4 & crack & 31 & 3.3 \\
\hline & álcool & 25 & 2.6 & tristeza & 28 & 3.5 \\
\hline & destruição & 25 & 2.8 & família & 26 & 3.5 \\
\hline & ruim & 13 & 2.4 & cigarro & 17 & 3.0 \\
\hline & remédios & 12 & 2.6 & depressão & 15 & 3.3 \\
\hline & violência & 12 & 2.8 & ilícitas & 14 & 3.4 \\
\hline & & & & saúde & 13 & 3.1 \\
\hline & & & & roubo & 12 & 4.1 \\
\hline & & & & solidão & 12 & 3.5 \\
\hline & & & & problemas & 12 & 3.2 \\
\hline \multirow{19}{*}{$f<11$} & Elemento & $f$ & OME & Elemento & $f$ & OME \\
\hline & amigos & 9 & 2.6 & influência & 11 & 3.1 \\
\hline & festa & 9 & 1.9 & morador de rua & 10 & 3.4 \\
\hline & vida & 8 & 2.5 & dependente & 10 & 3.2 \\
\hline & perdição & 7 & 2.1 & loucura & 9 & 3.8 \\
\hline & adolescentes & 7 & 2.9 & pó & 9 & 3.4 \\
\hline & jovens & 6 & 2.8 & Proerd & 8 & 3.0 \\
\hline & dinheiro & 6 & 1.8 & abandono & 8 & 3.2 \\
\hline & & & & Iança-perfume & 8 & 4.1 \\
\hline & & & & prisão & 8 & 3.8 \\
\hline & & & & pobreza & 7 & 3.3 \\
\hline & & & & sofrimento & 7 & 3.1 \\
\hline & & & & cadeia & 7 & 3.3 \\
\hline & & & & bala & 7 & 4.3 \\
\hline & & & & dor & 7 & 3.4 \\
\hline & & & & perigo & 7 & 3.4 \\
\hline & & & & festas & 6 & 4.3 \\
\hline & & & & crime & 6 & 3.3 \\
\hline & & & & agressividade & 6 & 3.3 \\
\hline
\end{tabular}

Figura 2. Análise prototípica. Teste de evocação.

Fonte: Figura elaborada pelos autores

Para visualizar a organização das representações sociais e confirmar a centralidade do elemento vício, foi realizada uma análise de similitude. Essa análise de coocorrência possibilita a visualização da organização da representação a partir da força com que os elementos se ligam uns aos outros (Vergès, Junique, Barbry, Scano \& Zeliger, 
2002; Moliner, 1994). Assim, no intento de verificar a conexidade dos elementos, a análise apresentará grafos da relação dos principais elementos encontrados.

Como forma de compor o diagnóstico da estrutura da RS sobre as drogas, foi realizada uma análise de similitude global. Esta análise se baseia na teoria dos grafos e identifica conexões entre as categorias evocadas a partir de uma matriz de coocorrências. $\mathrm{O}$ estudo da

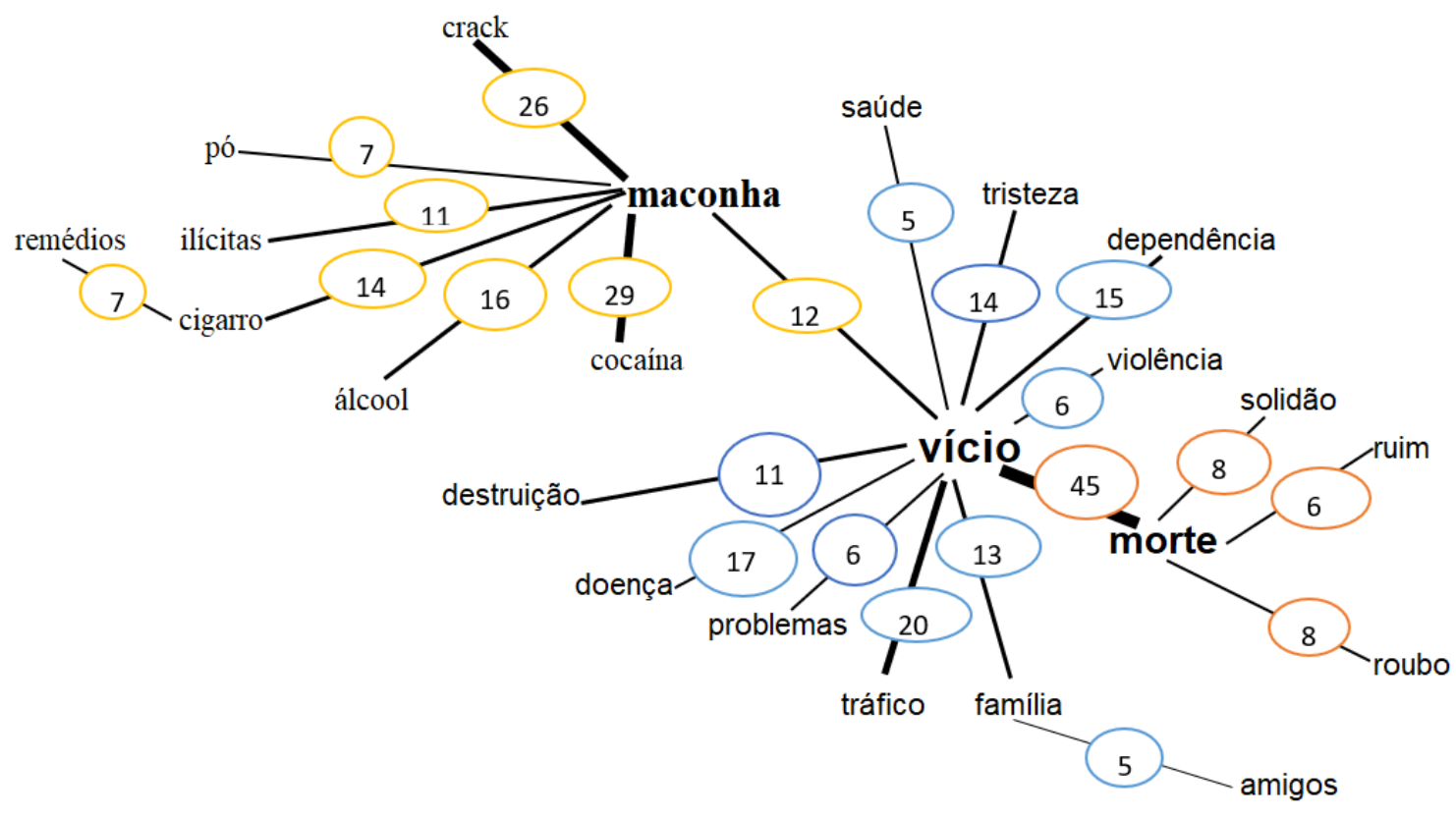

Figura 3. Análise de similitude, teste de evocação.

Fonte: Figura elaborado pelos autores

Para esta análise, partiu-se de 325 evocações ao todo, e, por fim, após a seleção foram analisadas 29 palavras em suas coocorrências com frequência mínima igual a nove. O resultado da análise de similitude (Figura 3) mostra a árvore de conexões, onde os vértices com as palavras em letras maiores indicam os elementos com maior frequência, já as arestas, linhas de diferentes espessuras, representam as ligações e coocorrências entre os elementos evocados, indicando o número de coocorrências entre elas.

A análise de similitude demonstra que o elemento "vício" assume papel organizador da representação social das drogas, pois apresenta forte conexidade com as palavras "morte" e "maconha", que organizam três comunidades ao seu entorno, por meio das palavras que se conectam a elas formando a estrutura maior. A conexidade dos elementos permite visualizar a organização de uma RS (Marchand, \& Ratinaud, 2012). Os resultados são ilustrados na árvore, que mostra as relações entre os elementos a partir do filtro de um número mínimo de coocorrências (Figura 3). partir destes elementos, os demais se organizam no entorno e adquirem sentido. Observa-se que, não apenas os elementos organizadores, mas também, a maior parte dos elementos que compõem a árvore expressa um sentido negativo.

Em complemento realizou-se uma análise de frequência multivariada para verificar quais termos apareceriam com maior frequência, dando indícios de representações diante da tarefa de escolha de duas palavras mais importantes dentre as evocadas. Nesta tarefa, os participantes tinham maiores condições de avaliar as palavras por eles evocadas e escolher as que considerassem mais importantes na associação ao objeto drogas. Pôde-se verificar, conforme apresentado na Tabela 1, que as palavras vício e morte ainda 
foram mantidas como principais elementos, apresentando as maiores frequências.

De modo a verificar como estas palavras se estruturam e organizam a representação, realizou-se a análise prototípica.
A Figura 4, apresenta os resultados obtidos para o conjunto de dados relativos às duas palavras mais importantes. A análise foi empreendida a partir da frequência média 6 e OME de 1,5.

Tabela 1

Análise multivariada das duas palavras escolhidas como mais importantes

\begin{tabular}{|c|c|c|c|}
\hline \multicolumn{4}{|c|}{ Evocações de maior frequência. Duas palavras mais importantes } \\
\hline Palavra & $f$ & Palavra & $f$ \\
\hline vício & 56 & remédio & 5 \\
\hline morte & 51 & jovens & 5 \\
\hline maconha & 26 & amigos & 5 \\
\hline família & 19 & violência & 5 \\
\hline dependência & 15 & festa & 5 \\
\hline tráfico & 14 & crime & 4 \\
\hline destruição & 14 & sofrimento & 4 \\
\hline depressão & 10 & adolescentes & 4 \\
\hline saúde & 10 & câncer & 4 \\
\hline crack & 9 & problemas & 4 \\
\hline tristeza & 9 & cigarro & 4 \\
\hline doenças & 8 & cadeia & 4 \\
\hline álcool & 8 & Bebidas alcoólicas & 4 \\
\hline cocaína & 7 & perigo & 4 \\
\hline influência & 7 & & \\
\hline
\end{tabular}

Nota: Tabela elaborada pelos autores

\begin{tabular}{|c|c|c|c|c|c|c|}
\hline \multicolumn{7}{|c|}{ Evocações a partir do termo indutor "Drogas" $(n=262)$} \\
\hline & ON & $=$ & & OM & 1.5 & \\
\hline \multirow{10}{*}{$f>=6.6$} & Elemento & $\boldsymbol{f}$ & OME & Elemento & $\boldsymbol{f}$ & OME \\
\hline & vício & 56 & 1.3 & morte & 51 & 1.5 \\
\hline & família & 19 & 1.4 & maconha & 26 & 1.5 \\
\hline & destruição & 14 & 1.4 & dependência & 15 & 1.6 \\
\hline & doenças & 8 & 1.1 & tráfico & 14 & 1.7 \\
\hline & álcool & 8 & 1.4 & depressão & 10 & 1.7 \\
\hline & influência & 7 & 1.4 & saúde & 10 & 1.6 \\
\hline & & & & crack & 9 & 1.7 \\
\hline & & & & tristeza & 9 & 1.8 \\
\hline & & & & cocaína & 7 & 1.7 \\
\hline \multirow{9}{*}{$f<6.6$} & Elemento & $f$ & OME & Elemento & $f$ & OME \\
\hline & remédio & 5 & 1.0 & sofrimento & 4 & 1.8 \\
\hline & jovens & 5 & 1.4 & câncer & 4 & 1.8 \\
\hline & amigos & 5 & 1.4 & cigarro & 4 & 1.8 \\
\hline & violência & 5 & 1.2 & cadeia & 4 & 1.8 \\
\hline & festa & 5 & 1.2 & bebidas alcoólicas & 4 & 1.5 \\
\hline & crime & 4 & 1.2 & perigo & 4 & 1.5 \\
\hline & adolescentes & 4 & 1.2 & & & \\
\hline & problemas & 4 & 1.2 & & & \\
\hline
\end{tabular}

Figura 4. Análise prototípica da escolha das duas palavras mais importantes

Fonte: Figura elaborada pelos autores

No primeiro quadrante, zona do núcleo, verifica-se as palavras vício, família, destruição, doenças, álcool e influência, e esta conformação na zona do núcleo apesar de se assemelhar aos resultados anteriores, inclui o elemento influência. Essa inclusão demonstra que ao refletir sobre as palavras evocadas, a representação social das drogas inclui a ideia de motivos pelos quais o uso ocorre. Na primeira periferia, mantém-se a ideia de consequências 
do uso de drogas como elementos representativos associados às práticas de uso.

$\mathrm{Na}$ zona de contraste, apenas a palavra ruim, e na periferia longínqua apenas as palavras depressão e dependente são comuns à análise geral de palavras evocadas. Verifica-se que em todo o restante há divergências e as palavras transitam entre os quadrantes das diferentes análises, no entanto, o sentido semântico de caráter negativo é também expressado nesta análise. Há na zona de contraste elementos que se associam ao contexto de uso, como por exemplo, festa e amigos, o que denota que, para pequenos grupos, as drogas podem ter outros sentidos que não apenas os negativos.

A fim de confirmar estas análises, optou-se novamente pela análise de similitude para verificar a estrutura e suas coocorrências. A análise referente às duas palavras escolhidas como as mais importantes do teste de evocações é apresentada na Figura 5 e contou com total de 188 evocações, após a seleção, foram analisadas 15 palavras em suas coocorrências com frequência mínima igual a 7.

As palavras morte e vício coocorrem 13 vezes e continuam assumindo caráter central na estrutura das RS. Nesta estrutura a palavra tráfico aparece como um conector entre as palavras maconha e vício.

Por meio das transcrições das respostas dadas à pergunta: $\mathrm{O}$ que leva alguém a usar drogas? construiu-se um corpus textual composto 262 textos e que por meio da análise de CHD se desdobraram em 326 segmentos de textos (STs). Destes, 303 STs $(92,94 \%)$ foram aproveitados na análise resultando em três classes. A Figura 6 apresenta o resultado da CHD onde verifica as palavras mais significativas com a frequência de ocorrências da palavra em segmentos de texto na classe, seguidas do valor de qui-quadrado.

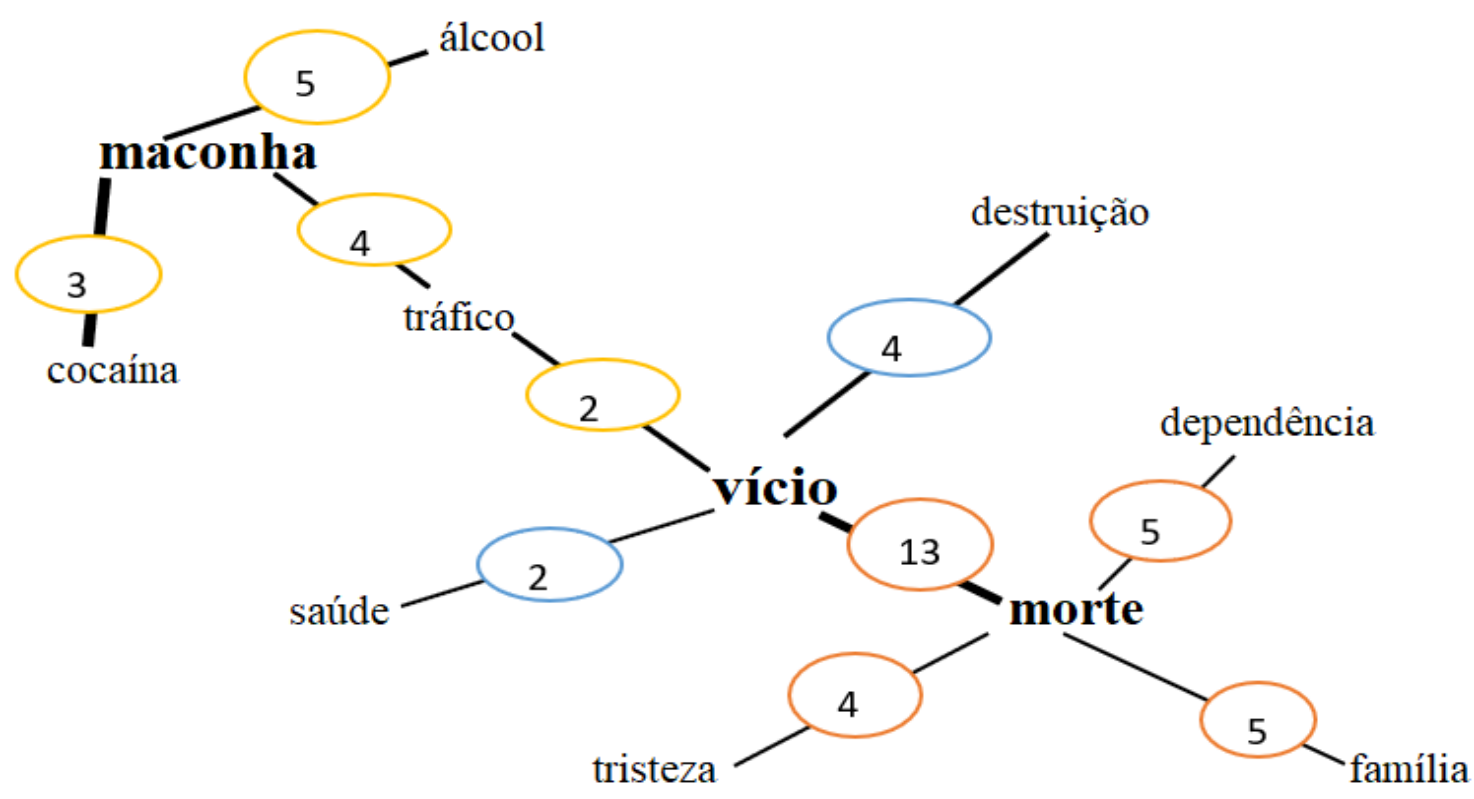

Figura 5. Análise de similitude da escolha das duas palavras mais importantes

Fonte: Figura elaborada pelos autores 


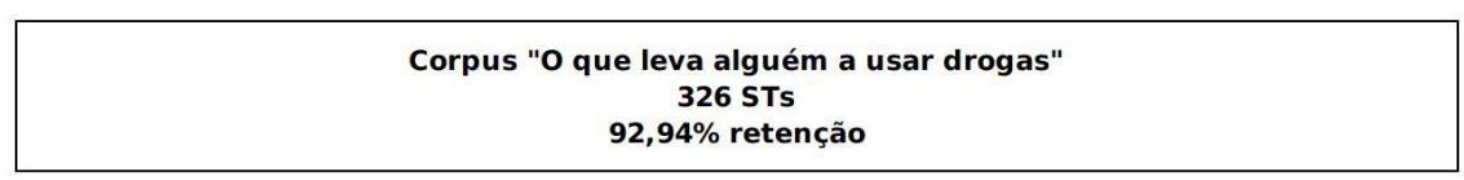

\begin{tabular}{|c|c|c|c|c|c|c|c|c|}
\hline \multicolumn{3}{|c|}{$\begin{array}{c}\text { Classe } 1 \\
21,78 \%-66 \text { STs }\end{array}$} & \multirow{2}{*}{\multicolumn{3}{|c|}{\begin{tabular}{|c|} 
Classe 2 \\
$29,04 \%-88$ STs \\
$\begin{array}{c}\text { Esquecer problemas e } \\
\text { falta de informação }\end{array}$
\end{tabular}}} & \multicolumn{3}{|c|}{$\begin{array}{c}\text { Classe } 3 \\
49,17 \% \text { - } 149 \text { STs }\end{array}$} \\
\hline \multicolumn{3}{|c|}{ Incentivo de más companhias } & & & & \multicolumn{3}{|c|}{$\begin{array}{c}\text { Aceitação, influências e } \\
\text { curiosidade }\end{array}$} \\
\hline Palavra & $f$ & $x^{2}$ & Palavra & $f$ & $x^{2}$ & Palavra & $f$ & $x^{2}$ \\
\hline parar & 9 & 28,25 & algo & 20 & 22,87 & realidade & 19 & 17,99 \\
\hline acabar & 27 & 24,73 & mal & 8 & 20,08 & depressão & 27 & 15,79 \\
\hline começar & 12 & 20,37 & querer & 30 & 16,90 & fugir & 19 & 13,13 \\
\hline conseguir & 13 & 19,38 & dizer & 10 & 12,80 & influência & 61 & 12,52 \\
\hline louco & 5 & 18,26 & onda & 5 & 12,42 & moda & 10 & 10,69 \\
\hline levar & 19 & 15,75 & contar & 6 & 11,17 & bem & 10 & 10,69 \\
\hline festa & 9 & 15,56 & mundo & 10 & 10,84 & problema & 56 & 10,38 \\
\hline ficar & 12 & 14,95 & tentar & 4 & 9,90 & diversão & 14 & 7,93 \\
\hline companhia & 4 & 14,56 & triste & 4 & 9,9 & curiosidade & 30 & 7,44 \\
\hline perigoso & 4 & 14,56 & amenizar & 4 & 9,9 & pressão & 11 & 6,83 \\
\hline incentivar & 4 & 14,56 & oferecer & 5 & 8,75 & fuga & 6 & 6,33 \\
\hline cabeça & 6 & 13,66 & obrigar & 6 & 8,42 & forma & 14 & 6,26 \\
\hline ajudar & 6 & 13,66 & usar & 45 & 8,2 & efeito & 8 & 5,85 \\
\hline consumir & 5 & 13,61 & informação & 4 & 7,4 & sentimento & 5 & 5,25 \\
\hline tornar & 8 & 12,6 & gostar & 7 & 6,63 & grupo & 9 & 4,87 \\
\hline vida & 15 & 12,18 & dor & 6 & 6,37 & dificuldade & 4 & 4,19 \\
\hline emocional & 5 & 10,37 & ruim & 7 & 5,2 & encaixar & 4 & 4,19 \\
\hline momento & 6 & 8,87 & acabar & 24 & 4,81 & círculo & 4 & 4,19 \\
\hline casa & 6 & 5,84 & entrar & 5 & 4,46 & conviver & 4 & 4,19 \\
\hline próprio & 7 & 5,74 & amigo & 34 & 4,37 & angústia & 4 & 4,19 \\
\hline vontade & 8 & 4,91 & precisar & 4 & 4,2 & amizade & 13 & 4,07 \\
\hline acontecer & 5 & 4,83 & solução & 4 & 4 & social & 8 & 3,93 \\
\hline achar & 20 & 3,92 & pensar & 4 & 4,2 & & & \\
\hline & & & esquecer & 12 & 4,04 & & & \\
\hline
\end{tabular}

Figura 6. Dendrograma da $\mathrm{CHD}$ do corpus $\mathrm{O}$ que leva alguém a usar drogas

Fonte: Figura elaborado pelos autores

A classe 3 com 49,17\% dos STs foi chamada Aceitação, influências e curiosidade. Esta classe apresenta conteúdos associados à concepção de que o que leva alguém a utilizar drogas é a aceitação nos grupos, as influências de amigos e a curiosidade de experimentar. Ilustra-se o seu conteúdo pelos trechos: "muitas coisas, como a curiosidade de experimentar, ou por influência de amigos"; "a curiosidade de experimentar coisas novas ou a influência de pessoas do seu círculo social"; "problemas familiares, sociais, círculo social, aprovação social, diversão e outras milhares de coisas"; $e$ não há um motivo específico, pode ser curiosidade, pressão social para se integrar com um grupo, pode ser uma forma de tentar escapar da realidade;

A classe 1 com $21,78 \%$ dos STs foi chamada Incentivo de más companhias e está associada a participantes que não tiveram experiência de consumo e traz a noção de que o mais significativo para que as pessoas experimentem drogas é a vontade deliberada de experimentar, e também a influência de más companhias. O conteúdo destas ideias pode ser ilustrado a partir das seguintes respostas: "eu acho que muitas vezes o que acaba levando são as más companhias, mas também pode vir de 
parentes próximos"; "pode ser desde as companhias que a pessoa tem, ter deixado com que essas companhias a influenciem"; e

incentivo de amigos, lugar onde mora, ver alguém usando e sentir à vontade de experimentar e aí acaba experimentando, e já vicia naquilo e não consegue mais largar.

A classe 2 com 29,04\% dos STs foi chamada Esquecer problemas e falta de informação e está mais próxima da classe 1 . Esta classe revela a ideia de que a experimentação se dá por falta de informações e como um refúgio para esquecer os problemas. Os trechos a seguir exemplificam esse contexto:

às vezes pode ser por influência dos amigos $e$ às vezes a falta de informação"; "quando acontece algo ruim e a pessoa quer esquecer ou não aguenta o fardo e acaba usando drogas para ajudar a superar, mas muitas vezes acaba se viciando; muitos vão por influências, porque cedem para experimentar e acabam gostando, mas também entram nas drogas por outros motivos, porque acham que a droga pode ajudar a esquecer dos problemas.

Para este conteúdo também foi realizada análise de similitude. Partiu-se de 275 evocações ao todo e, após a seleção, foram analisadas 32 palavras em suas coocorrências, com frequência mínima igual a 8 .

É possível verificar, diante da disposição da árvore de similitudes (Figura 7), que as palavras problema, amigo e influência assumem papel de centralidade, organizando as comunidades ao seu entorno. Ligadas fortemente ao termo influência estão os termos experimentar e curiosidade, que exprimem uma necessidade da fase de desenvolvimento dos participantes e do esperado diante do desconhecido. Em outras palavras, os amigos e as companhias podem influenciar sobre a curiosidade e a experimentação.

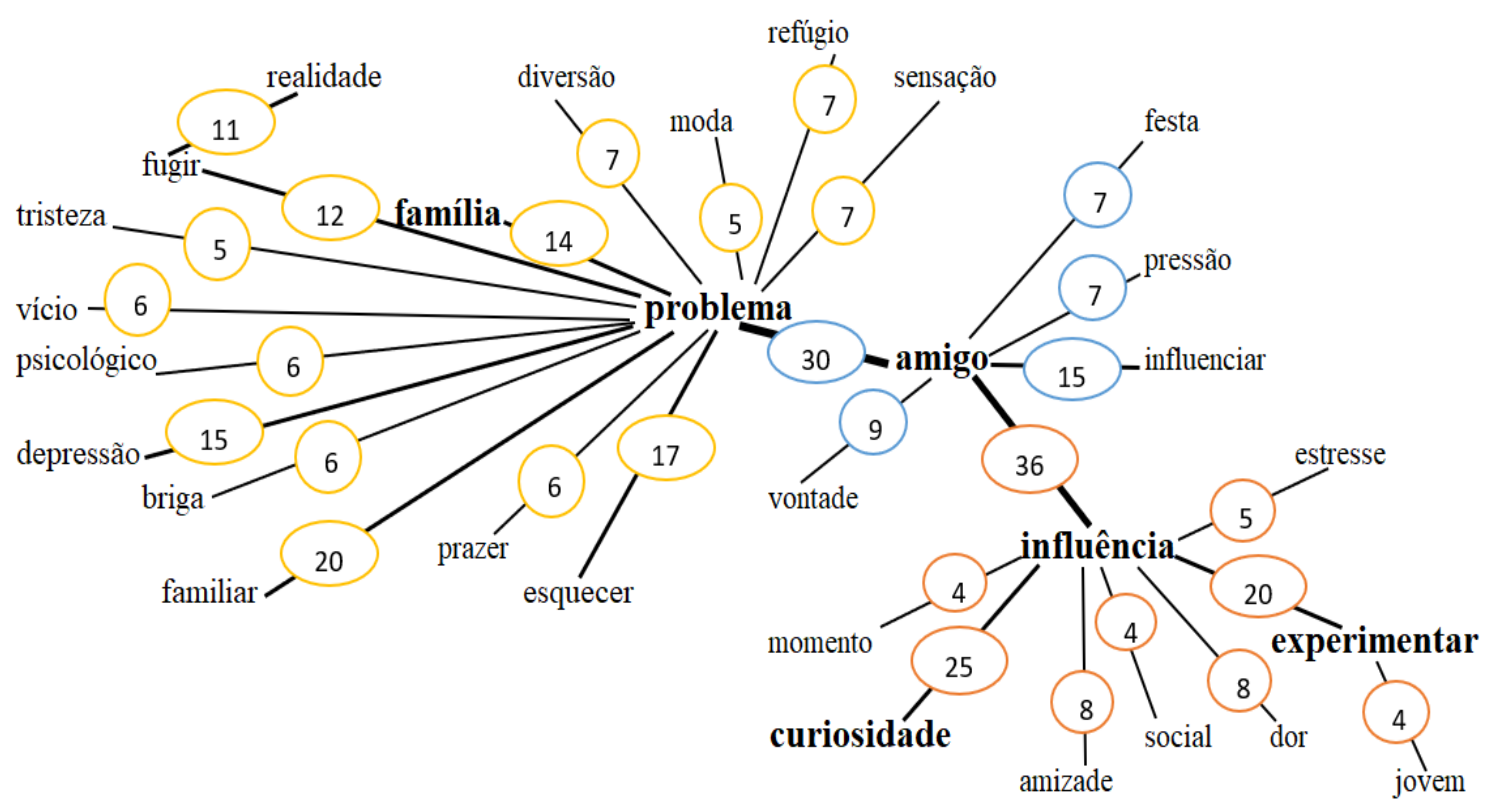

Figura 7. Análise de similitude corpus "o que leva alguém a usar drogas"

Fonte: Figura elaborada pelos autores

A palavra problema organiza uma comunidade que parece trazer de modo amplo dois aspectos representacionais, um deles se refere aos tipos de problemas ocasionados pelo uso das drogas, como depressão, vício, tristeza, e o outro traz aspectos de finalidade do uso, como estratégia de enfrentamento, como para esquecer os problemas, se divertir, enturmar-se, obter sensação de prazer, entre outros. 


\section{Discussão}

A análise da estrutura das representações foi efetuada em dois níveis. $\mathrm{O}$ primeiro foi baseado no cruzamento das frequências de ocorrência dos conceitos associados ao objeto "drogas" com a sua ordem de evocação, permitindo determinar os elementos mais compartilhados do núcleo central e do sistema periférico, de forma livre e espontânea. Estes foram confirmados ou não no nível seguinte, a partir da importância que essas evocações possuem para o indivíduo em termos das representações. Desse modo, o primeiro nível representa a disponibilidade da informação na mente dos participantes e o segundo representa o processamento controlado das informações relativas ao objeto das drogas.

A partir do teste de evocações livres, verificou-se que o termo vício foi o principal organizador da RS das drogas para os adolescentes deste estudo, evidenciando sua centralidade a partir dos resultados da análise de similitude, estruturando comunidades e apresentando conexidade com as palavras morte e maconha, que por sua vez organizam outras comunidades ao seu entorno. Abric (2003) explica que os elementos centrais atribuem sentido aos demais elementos das RS, além de conferir estabilidade às RS. Os demais elementos evocados pelos participantes se ligam a algum destes três elementos que organizam em torno de si as comunidades ordenadas pelo termo vício.

A centralidade do elemento vício confere às RS das drogas um caráter de consequência, sendo percebidas como algo negativo e que, se usadas, causam severos danos, podendo levar à morte, sendo esta tanto física quanto representativa do prejuízo e interrupção das diversas esferas da vida. Como no estudo de Santos, Acioli Neto e Sousa (2012), a forte associação entre as drogas e morte está antes vinculada à dependência/vício. Por meio desta noção organizadora, desdobram-se os elementos periféricos, os quais apresentam as nuances das representações, sendo elas de ordem subjetivas ou objetivas, atreladas tanto aos aspectos mais individuais como também ao convívio social, sobretudo no contexto das práticas.

Quanto aos dados encontrados na análise prototípica proposta por Vergès, Junique, Barbry, Scano Zeliger (2002), localizados no primeiro quadrante, com possibilidade de serem elementos do núcleo central, encontram-se os elementos tráfico, destruição, ruim, violência, maconha e álcool, os quais indicam consequências maléficas e progressivas ao uso de drogas, assim, para os adolescentes participantes o uso de substâncias que causam dependência é algo ruim que traz graves consequências, como a violência e a destruição, podendo levar as pessoas a ações extremas como o tráfico. Defende-se que no contexto da prevenção ao uso de drogas, intervenções educativas que reforçam representações sociais ligadas ao medo, violência e destruição dificultam a ampliação do debate e a quebra de tabus relacionados às drogas, fazendo com que sejam diminuídas as possibilidades de lidar com a problemática a partir do contexto da saúde, como proposto por vários autores (Giacomozzi, 2011; Oliveira, Rodrigues, Porcino \& Reale, 2016; Andrade, Alves \& Bassani, 2018).

Para além, estes termos se associam ainda como fatores responsáveis pelas perdas afetivas, familiares e materiais, noções ancoradas a partir do elemento vício. Tais termos, enquanto elementos unificadores $\mathrm{e}$ estabilizadores das representações sociais das drogas, exprimem o caráter negativo atribuído a este objeto representacional. O contexto familiar é elemento recorrente nas menções ao uso de drogas. Assim, a família pode ser um fator de proteção ao uso, quando há existência de vínculos familiares fortes, apoio da família à construção de autonomia do adolescente, monitoramento parental e estabelecimento claro de regras e condutas sociais (Schenker \& Minayo, 2005). Por outro lado, as autoras ressaltam que a família também pode ser um fator de risco quando há valorização positiva do uso de drogas, além de aspectos relacionais como ausência de vínculos, baixo envolvimento materno, inconsistência no 
estabelecimento de disciplina, permissividade ou superproteção excessivas, conflitos familiares, educação autoritária e pouca afetividade, entre outros. A interação social é uma necessidade humana, todavia a adequação dos processos de interação segundo as normas de cada inserção grupal, seja familiar ou entre pares pode gerar contradições e ambivalências no adolescente, contribuindo para o aumento da exposição a riscos (Facundo, 2005).

No quadrante superior direito encontram-se os elementos evocados que indicam serem elementos do sistema periférico com alto grau de ativação. Estes elementos são responsáveis pela concretização do núcleo central, no que se refere a tomadas de posição e de condutas; orientam, assim, as práticas dos sujeitos (Abric, 1998). Desse modo, desdobram a conotação negativa dos elementos do núcleo central da representação social das drogas. São os elementos: morte, doença, cocaína, crack, tristeza, família, cigarro, depressão, ilícitas, saúde, roubo, solidão e problemas. Observa-se que estes termos remetem aos elementos potenciais do núcleo, trazendo sentidos e características predominantemente negativas, ou seja, aspectos ligados aos desdobramentos do vício, que levam à morte e acarretam em doenças, problemas de saúde e familiares, notadamente quando o uso é de substâncias como o crack e a cocaína. Além disso, extrapolando as questões de ordem individual, aparece um indicativo que chama a atenção para questões de ordem social que se materializa na palavra roubo. Tais elementos objetificam e tornam pragmáticas as normas e valores presentes no núcleo da RS.

Enquanto os elementos centrais em geral são mais abstratos e possuem natureza normativa, os elementos periféricos referem-se a scripts de práticas concretas, de natureza mais funcional, que descrevem e determinam ações (Abric, 2003; Flament, 2001), configurando assim a RS como um todo. Os elementos mais concretos são característicos da periferia da RS e ao estarem ligados aos elementos centrais, permitem que as RS sejam um guia prático de leitura para a realidade, relacionando-se com eventos do cotidiano dos atores sociais
(Campos \& Rouquette, 2003). Deste modo, pode-se verificar que as RS das drogas se alicerçam predominantemente nas ideias relacionadas às consequências negativas, associadas às normas e abstrações características dos elementos do núcleo central.

No que diz respeito à tarefa de elencar as duas palavras mais importantes das evocações, evidenciou-se, no teste de frequência multivariada, que os resultados obtidos se aproximam da análise geral de evocações, com as maiores frequências atribuídas aos termos vício e morte. No entanto, a ocorrência de termos como influência, amigos, festa e remédios permite entender que ao desenvolver a tarefa refletida, a representação passa a incluir elementos do contexto de práticas de uso de drogas.

A análise da CHD referente ao corpus $\mathrm{O}$ que leva alguém a usar drogas indica as razões pelas quais os sujeitos da pesquisa consideram que o uso de drogas se inicia. Os resultados apresentaram três contextos lexicais e o maior deles, representando praticamente metade da amostra, refere-se ao desejo de querer ser aceito e integrar-se nos grupos, o papel importante das influências de amigos para estes comportamentos e, ainda, outro aspecto relevante é a curiosidade de experimentar. Observa-se que, dentre as justificativas elencadas, duas delas estão relacionadas ao convívio social e também à pressão social imposta para integrar e ser aceito em grupos, enquanto que um terceiro fator, a curiosidade de experimentar, é algo que, apesar das influências ambientais, é atribuído a um lócus individual. Para Sierra \& Mesquita (2006) devido à adolescência ser uma de maior vulnerabilidade os adolescentes tornam-se mais submissos ao ambiente físico e social, podendo apresentar importantes agravos ao seu estado de saúde psicológico, social e mental.

Outra classe, que se relaciona à primeira, aponta também para o contexto de influências presentes nas relações sociais, no entanto, associado a um caráter negativo em relação à influência exercida, pois estabelece associação com a ideia de más companhias. 
Outro aspecto refere-se à vontade deliberada de experimentar, que, de outra forma, corresponde à curiosidade expressa, localizando novamente no indivíduo a causa para a prática de uso de drogas. No terceiro contexto, os pesquisados consideram que a experimentação ocorre por carência de informações a respeito do assunto e, também, como uma forma de se refugiar para esquecer os problemas.

Observa-se que o primeiro e o segundo contexto apresentam semelhanças, sendo que influências de amigos e influência de más companhias apresentam, em comum, a influência grupal como fator que contribui para a experimentação. A curiosidade de experimentar, presente no primeiro contexto, e a vontade deliberada, presente no segundo, também apresentam semelhanças, partindo-se da ideia de que a experimentação ocorre por ação que parte de desejo do próprio indivíduo que experimenta. Ao encontro dos dados obtidos, Silva e Padilha (2013) afirmam que os sujeitos de sua pesquisa, ao serem indagados a respeito da motivação para alguém se aproximar da bebida alcoólica, relatam problemas de caráter familiar ou social. Deste modo, nos trechos de relatos citados dos participantes há a atribuição da experimentação a fatores tais como a fuga de problemas, a influência social e a busca por prazer. Neste contexto, a vontade deliberada refere-se à busca por prazer.

A análise de similitude demonstra duas visões predominantes a partir das palavras problema, amigo e influência, os principais fatores que os participantes da pesquisa elencaram como causadores do uso. $\mathrm{O}$ primeiro traz como referência o elemento problema, que se conecta a questões familiares, à fuga da realidade, ao esquecimento das dificuldades e ao sentimento de tristeza, sendo assim um refúgio capaz de curar coisas negativas. $\mathrm{O}$ outro se refere às ideias de que a vontade de experimentar, influenciada pelos amigos, está atrelada ao sentir-se bem nos ambientes de convivência, a busca pela diversão e sensações de prazer.
De acordo com Sousa (2017), o reconhecimento, das sensações positivas e do prazer como motivador do consumo de diferentes drogas vai ao encontro da hipótese de que o prazer gerado pelo consumo de drogas consiste em uma dimensão do objeto que é socialmente reconhecida e consensual. A ilegitimidade, entretanto, atribuída ao consumo de drogas para fins hedonistas, provoca tomadas de posição que não são consensuais. Deste modo, reconhecer o prazer como constituindo o objeto não implica, necessariamente, a adesão a atitudes favoráveis ao uso. Esse cenário fica expresso na associação que alguns indivíduos fazem entre o prazer obtido no uso e o desenvolvimento da dependência decorrente disso.

\section{Considerações finais}

Buscou-se investigar, compreender e descrever os conteúdos, as estruturas e a organização das RS elaboradas por adolescentes sobre as drogas. Visto que o fenômeno do uso e abuso de drogas tem suscitado inúmeras discussões em diversas esferas, e principalmente no que se refere às motivações que contribuem para o início do uso, este estudo buscou contribuir com o aumento do conhecimento a respeito desse fenômeno no campo científico da psicologia e da saúde.

Com relação ao teste de evocações que buscou contemplar a investigação das RS das drogas e a sua estrutura amparada na abordagem estrutural, encontrou-se como elemento central mais característico o elemento "vício", que esteve presente em todos os resultados e confere às RS das drogas um caráter negativo, convergindo com este outros elementos centrais encontrados na zona periférica da representação. Estes elementos denotam um ciclo de causalidades e consequências negativas. Desta forma, para os adolescentes participantes deste estudo, as RS das drogas são essencialmente negativas, com exceção do elemento "remédios", que explicita outra dimensão das RS das drogas, associada a uma possível função social positiva delas. No entanto, este elemento ultrapassa a noção de 
medicamentos socialmente aceitos, parecendo se tratar de uma associação à ação medicinal de drogas ilícitas, mais precisamente a maconha. Quanto à tarefa de elencar as duas palavras mais importantes das evocações, os elementos não diferem significativamente das análises anteriores, com as maiores frequências atribuídas aos termos "vício", "morte" e "maconha", novamente representações exprimindo caráter negativo, ainda que esta tarefa possa ser mais refletida do que a anterior.

As representações obtidas por meio das análises de conteúdo apresentaram aspectos que sugerem maior abrangência, e maior quantidade de variáveis evidenciadas. As justificativas dadas à escolha das duas palavras evocadas mais importantes se relacionam a noções como dificuldades para interromper o uso de drogas ligando aos aspectos do vício, mas também incluem as consequências do uso para a saúde e a destruição familiar e dos laços afetivos. Quanto ao pensamento dos participantes especificamente sobre as drogas, surgiram representações referentes aos malefícios causados à saúde, tanto em aspectos biológicos quanto psicológicos, e problemas familiares. Já os aspectos positivos aparecem sob as formas de prazer, diversão e o desejo de querer ser aceito e integrar-se nos grupos, o papel importante das influências de amigos para estes comportamentos e, ainda, a curiosidade de experimentar. Noções ligadas a efeitos medicinais de algumas drogas também foram observadas no conteúdo. Houve ainda a referência ao fato de as drogas oferecerem diversos perigos, de maneira que, se a pessoa começar a utilizar se viciará e tomará um caminho, percebido por este grupo de participantes, como sendo sem volta.

O questionamento sobre o que leva alguém a usar drogas fez com que emergissem elementos de representações, principalmente ligados ao convívio e influência social, curiosidade, prazer, diversão e ao desejo de experimentar, atrelados às companhias e à necessidade de aceitação nos grupos. Outro aspecto abrangente refere-se à dificuldade em lidar com problemas das mais diversas ordens e encontrar no uso das substâncias um refúgio.
Os motivos elencados para que tenha ocorrido a experimentação fez com que emergissem representações que vão ao encontro dos motivos apontados para o uso das drogas, que consistem na diversão, desejo e curiosidade de saber sobre as sensações e os efeitos causados pelas drogas; e também uma forma de fuga dos problemas e da realidade.

Diante dos resultados encontrados, vale ressaltar que Jodelet (1984) afirma que a elaboração representativa de um objeto consiste em mais que a apreensão de ideias, noções, imagens, modelos que concretizam as representações sociais, existindo também uma apreensão dos quadros categoriais e classificatórios que consistem nos princípios de ordem que articulam o sistema de pensamento e ação. A elaboração representativa de um objeto, portanto, refere-se também à influência das modalidades coletivas em que os membros da sociedade pertencem e organizam seus contextos referenciais. Deste modo, estas representações sobre as drogas, convergem para um cerne, a busca pela sensação de bemestar, a busca de sentimentos e emoções positivas, ou seja, ampliando-se o olhar, as drogas são essencialmente percebidas por estes participantes como positivas, no sentido em que são capazes de trazer estas sensações aos indivíduos imediatamente, desse modo, estes aspectos adquirem mais força se comparados à noções sobre desdobramentos negativos a longo prazo; o medo do vício, da morte, das perdas e da destruição da vida acabam perdendo na hierarquia das atitudes desenvolvidas pelos indivíduos.

A fim de contribuir para a mudança da realidade atual, são necessárias ações adaptadas para o contexto brasileiro que trabalhem o tema de modo transversal nas escolas, buscando envolver os familiares, tratando o assunto com naturalidade e versando sobre as suas mais diversas possibilidades, tanto positivas como negativas, com forte cunho informativo. Assim, há concordância com Fonseca, Sena, Santos, Dias e Costa (2013) que abordando o Estatuto da Criança e Adolescência - ECA, afirmam que as políticas públicas de intervenção devem proporcionar ações contextualizadas e que 
garantam que estas sejam alinhadas às prioridades existentes no contexto da infância e adolescência, sendo necessário o reconhecimento das demandas de crianças e adolescentes em relação aos fatores de proteção ao desenvolvimento, incluindo saúde, educação e lazer. Além disso, percebe-se que as dificuldades nas relações sociais, nos vínculos afetivos e em lidar com situações adversas na vida são potencializadores para a busca de uso, pois, diante do sentimento de incapacidade em lidar com emoções negativas, os indivíduos tornam-se propensos à busca da supressão destas emoções por meio de sensações de prazer e de emoções positivas que lhes proporcionem a fuga da realidade adversa.

Como limitações desta pesquisa, é necessário ressaltar que o fato de a coleta de dados ser realizada no ambiente escolar pode ter contribuído para o enviesamento dos dados no que diz respeito a respostas socialmente esperadas. Além disso, a formalidade estabelecida entre as instituições escolares e a equipe de coleta de dados gerou um distanciamento de papeis entre os adolescentes e pesquisadores, o que pode ter contribuído para a criação de uma maior pressão normativa e consequentemente um efeito de artificialidade sobre as respostas dadas.

Desse modo, consideram-se profícuos trabalhos que viabilizem discussões diretas e indiretas sobre o tema, tangenciando-o e abarcando os conteúdos, de maneira que o assunto não seja tratado como tabu, favorecendo assim a expressão do pensamento social naturalmente produzido pelos adolescentes sobre essa importante questão.

\section{Referências}

Abric, J. C. (1998). A abordagem estrutural das representações sociais. In A. S. P. Moreira, \& D. C. Oliveira (Orgs.), Estudos interdisciplinares de representação social (pp. 27-38). Goiânia: AB.

Abric, J. C. (2003). La recherche du noyau central et de la zone muette des représentations sociales. In J. C. Abric (Org.), Méthodes d'étude des représentations sociales (pp. 59-80). Ramonville Sant-Agne: Érès.

Andrade, S. F. O., Alves, R. S. F., \& Bassani, M. H. P. A. (2018). Representações sociais sobre as drogas: um estudo com adolescentes em conflito com a lei. Psicologia: Ciência e Profissão, 38(3), 437-449. doi: $\underline{10.1590 / 1982-}$ 37030000742017

Bastos, F. I. P. M., Vasconcellos, M. T. L., De Boni, R. B., Reis, N. B., \& Coutinho, C. F. S. (Orgs.). (2017). III Levantamento Nacional sobre o uso de drogas pela população brasileira. Rio de Janeiro: FIOCRUZ/ICICT. Recuperado de https://www.arca.fiocruz.br/handle/icict/34 $\underline{614}$

Blaudt, V. L., \& Rangel, M. (2018). Diálogos exequíveis entre representações sociais e outros paradigmas da psicologia social. Psicologia \& Sociedade, 30, 1-10. doi: 10.1590/1807-0310/2018v30184257

Carlini, E. L. A., Noto, A. R., Sanchez, Z. V. M., Carlini, C. M. A., Locatelli, D. P., Abeid, L. R., ... Moura, Y. G. (2010). VI Levantamento Nacional sobre o Consumo de Drogas Psicotrópicas entre Estudantes do Ensino Fundamental e Médio das Redes Pública e Privada de Ensino nas 27 Capitais Brasileiras. São Paulo: CEBRID Centro Brasileiro de Informações sobre Drogas Psicotrópicas, UNIFESP Universidade Federal de São Paulo. Recuperado de https://www.cebrid.com.br/wpcontent/uploads/2012/10/VI-LevantamentoNacional-sobre-o-Consumo-de-DrogasPsicotr\%C3\%B3picas-entre-Estudantes-doEnsino-Fundamental-e-M\%C3\%A9diodas-Redes-P\%C3\%BAblica-e-Privada-deEnsino-nas-27-Capitais-Brasileiras.pdf

Campos, P. H. F., \& Rouquette, M.-L. (2003). Abordagem estrutural e componente afetivo das representações sociais. Psicologia: Reflexão e Crítica, 16(3), 435-445.

Recuperado de: 
http://www.scielo.br/pdf/prc/v16n3/v16n3a $\underline{\text { 03.pdf }}$

Czeresnia, D. (2003). O conceito de saúde e a diferença entre prevenção e promoção. In: Czeresnia, D., \& Freitas, C. M. (Orgs.). Promoção da saúde: conceitos, reflexões, tendências (pp. 39-53). Rio de Janeiro: Ed. Fiocruz.

Essau, C. A. (2011). Comorbidity of substance use disorders among community based and high-risk adolescentes. Psychiatry

Research, 185, 176-184. doi: 10.1016/j.psychres.2010.04.033

Facundo, G. (2005). Adquisición del uso de alcohol em um grupo de adolescentes mexicanos: el efecto de la relación com amigos. SMAD - Revista Eletrônica Saúde Mental Álcool e Drogas, 1(2), 1-13.

Recuperado de

http://pepsic.bvsalud.org/scielo.php?script= sci arttext\&pid=S180669762005000200003

Flament, C. (2001). Estrutura e dinâmica das representações sociais. In D. Jodelet (Org.). As representações sociais (pp. 173-186). Rio de Janeiro: UERJ.

Flament, C., Guimelli, C., \& Abric, J.-L. (2006). Effets de masquage dans l'expression d'une représentation sociale. Cahiers Internationaux de Psychologie Sociale, 69, 15-31. doi: 10.3917/cips.069.0015

Fonseca, F. F., Sena, R. K. R., Santos, R. L. A., Dias, O. V., \& Costa, S. M. (2013). As vulnerabilidades na infância e adolescência e as políticas públicas brasileiras de intervenção. Rev Paul Pediatr, 31(2), 258264. doi: $10.1590 / \mathrm{S} 0103-$ 05822013000200019

Giacomozzi, A. I. (2011). Representações sociais da droga e vulnerabilidade de usuários de CAPSad em relação às DST/HIV/AIDS. Estudos e Pesquisas em Psicologia, 11(3). Recuperado de http://pepsic.bvsalud.org/scielo.php?script= sci arttext\&pid=S180842812011000300004

Giacomozzi, A. I., Itokasu, M. C., Figueiredo, C. D. S., Luzardo, A. R., \& Vieira, M. (2012). Levantamento sobre uso de álcool e outras drogas e vulnerabilidades relacionadas de estudantes de escolas públicas participantes do Programa Saúde do Escolar/Saúde e Prevenção nas escolas no município de Florianópolis. Saúde e Sociedade, 21(3), 612-622. doi: 10.1590/S0104-12902012000300008

Hewstone, M. (2001). Representações sociais e causalidade. In D. Jodelet (Org.), as representações sociais (pp. 217-240). Rio de Janeiro: EdUERJ.

Jodelet, D. (1984). Répresentation sociale: phénomènes, concept et théorie. In $\mathrm{S}$. Moscovici (Ed.), Psychologie sociale (pp. 363-384). Paris: P.U.F.

Jodelet, D. (2001). Representações sociais: um domínio em expansão. In D. Jodelet (Org.). As representações sociais. Rio de Janeiro: EdUERJ.

Kristjansson, A. L., Sigfusdottir, I. D., Allegrante, J. P., \& Helgason, A. R. (2008). Social correlates of cigarette smoking among Icelandic adolescents: a populationbased cross-sectional study. BMC Public Health, 8(1), 86. Recuperado de https://bmcpublichealth.biomedcentral.com track/pdf/10.1186/1471-2458-8-86

Malta, D. C., Sardinha, L. M. V., Mendes, I. Barreto, S. M., Giatti, L., Castro, I. R. R., ... Crespo, C. (2010). Prevalência de fatores de risco e proteção de doenças crônicas nas transmissíveis em adolescentes: resultados da Pesquisa Nacional de Saúde do Escolar (PeNSE), Brasil, 2009. Ciência \& Saúde Coletiva, 15(supl. 2), 3009-3019.

Marchand, P., \& Ratinaud, P. (2012). L'analyse de similitude appliqueé aux corpus textueles: les primaires socialistes pour l'election présidentielle française. In Actes des 11eme Journées internationales d'Analyse statistique des Données Textuelles. JADT 2012 (pp. 687-699). Liège, Belgique. Recuperado de http://lexicometrica.univparis3.fr/jadt/jadt2012/Communications/Ma rchand, \%20Pascal\%20et\%20al.\%20\%20L \%27analyse\%20de\%20similitude \%2 0appliquee\%20aux\%20corpus\%20textuels. $\underline{\mathrm{pdf}}$ 
Melo, J. R. F. (2013). Representações sociais de dependentes químicos acerca do crack, do usuário de drogas e do tratamento.

Dissertação de mestrado, Universidade

Federal da Paraíba, João Pessoa, PB.

Recuperado de

https://repositorio.ufpb.br/jspui/handle/tede 17113

Minto, E. C., Pedro, C. P., Netto, J. R. C., Bugliani, M. A. P., \& Gorayeb, R. (2006). Ensino de habilidades de vida na escola: uma experiência com adolescentes. Psicologia em Estudo, 11(3), 561-568. doi: 10.1590/S1413-73722006000300012

Moliner, P. (1994). Les méthodes de répérage et d'identification du noyau des representations sociales. In C. Guimelli (Org.), Structures et Transformations des Representations Sociales. Neuchâtel: Delachaux et Niestlé

Moliner, P. (2009). Attribution causale et représentations sociales. In P. Rateau \& P. Moliner (Orgs.), Représentations sociales et processus sociocognitifs (pp. 69-84). Rennes, FR: Press Universitaires de Rennes.

Oliveira, J. F., Rodrigues, A. S., Porcino, C. A., \& Reale, M. J. O. U. (2016). Imaginário de presidiárias sobre o fenômeno das drogas. Revista Eletrônica de Enfermagem, 18. doi: $\underline{0.5216 / \text { ree.v18.31072 }}$

Organización Mundial de la Salud - OMS. (1995). La salud de los jovens: um reto y uma esperanza. Ginebra: OMS; 1995.

p.120. Recuperado de

https://apps.who.int/iris/bitstream/handle/1 0665/37632/9243561545spa.pdf?sequence $=1 \&$ is 1 llowed $=\mathrm{y}$

Ratinaud, P. (2009). IRAMUTEQ: Interface de $\mathrm{R}$ pour les analyses

multidimensionnelles de textes et de questionnaires [Computer software].

Santos, M. F. S., Acioli Neto, M. L., \& Sousa, Y. S. O. (2012). Representações sociais do crack na imprensa pernambucana. Estudos de Psicologia, 29(3), 379-386. doi: $\underline{\text { 10.1590/S0103-166X2012000300008 }}$

Seleghim, M. R., Marangoni, S. R., Marcon, S. S., \& Oliveira, M. L. F. (2011). Vínculo familiar de usuários atendidos em uma unidade de emergência psiquiátrica. Revista Latino-Americana de Enfermagem, 19(5). doi: $\underline{10.1590 / S 0104-11692011000500014}$

Schenker, M., \& Minayo, M. C. S. (2005). Fatores de risco e de proteção para o uso de drogas na adolescência. Ciência \& Saúde Coletiva, 10(3), 707-717. doi: $\underline{10.1590 / \text { S1413-81232005000300027 }}$

Sierra, V. M., \& Mesquita, W. A. (2006). Vulnerabilidades e fatores de risco na vida de crianças e adolescentes. São Paulo em Perspec, 20(1), 148-55. Recuperado de http://produtos.seade.gov.br/produtos/spp/v 20n01/v20n01_11.pdf

Silva, S. É. D., \& Padilha, M. I. (2013). O alcoolismo na história de vida de adolescentes: uma análise à luz das representações sociais. Texto \& Contexto Enfermagem, 22(3), 576-84. doi: $\underline{\text { 10.1590/S0104-07072013000300002 }}$

Soares Filho, W. (2017). Memória e representações sociais sobre drogas e redução de danos de usuários e equipe multiprofissional de um CAPS AD (Dissertação de mestrado). Universidade Estadual do Sudoeste da Bahia, Vitória da Conquista, BA.

Sousa, Y. S. O. (2017). Drogas e normalização uma análise psicossocial desde a perspectiva das representações sociais (Tese de doutorado). Universidade Federal de Pernambuco, Recife, PE.

Recuperado de https://repositorio.ufpe.br/handle/12345678 9/23777

UNODC (ONU). (2008). Relatório Anual do Escritório das Nações Unidas sobre drogas e crimes. Recuperado de http://www.unodc.org/documents/wdr/WD $\underline{\text { R 2008/WDR } 2008 \text { eng web.pdf }}$

Vergès, P. (1992). L'évocation de l'argent: une méthode pour la définition du noyau central de la représentation. Bulletin de Psychologie, 45, 203-209.

Vergès, P., Junique, C., Barbry, W., Scano, S., \& Zeliger, R. (2002). Ensembles de programmes permettant l'analyse de similitude de questionnaires et de données numeriques. Aix en Provence, France: Université Aix en Provence 
Wachelke, J., \& Wolter, R. (2011). Critérios

de construção e relato da análise prototípica

para representações sociais. Psicologia

Teoria e Pesquisa, 27(4), 521-526. doi:

$\underline{10.1590 / \mathrm{S} 0102-37722011000400017}$

\section{Dados sobre os autores:}

- Ivana Lauffer Corrêa: Mestre em Psicologia pela Universidade Federal de Santa Catarina UFSC. Especialista em Psicologia Organizacional e do Trabalho e em Psicologia Clínica.

- Jean Paulo da Silva: Doutorando do Programa de Pós-Graduação em Psicologia da Universidade Federal de Santa Catarina - UFSC. Professor do curso de Psicologia da UNIVINCI e UNISOCIESC.

- Andréa Barbará da Silva Bousfield: Doutora em Psicologia. Coordenadora do Laboratório de Psicologia Social da Comunicação e Cognição - LACCOS. Professora do Departamento de Psicologia e do Programa de Pós-Graduação em Psicologia da Universidade Federal de Santa Catarina - UFSC.

- Andréia Isabel Giacomozzi: Doutora em Psicologia. Professora do Departamento de Psicologia e do Programa de Pós-Graduação em Psicologia da Universidade Federal de Santa Catarina UFSC.

Declaração de Direito Autoral

A submissão de originais para este periódico implica na transferência, pelos autores, dos direitos de publicação impressa e digital. Os direitos autorais para os artigos publicados são do autor, com direitos do periódico sobre a primeira publicação. Os autores somente poderão utilizar os mesmos resultados em outras publicações indicando claramente este periódico como o meio da publicação original. Em virtude de sermos um periódico de acesso aberto, permite-se o uso gratuito dos artigos em aplicações educacionais e científicas desde que citada a fonte conforme a licença CC-BY da Creative Commons. 